\title{
Finite Element Simulation of Residual Stress Determination Based on Spherical Indentation Accumulation Morphology
}

\author{
Xiaochen He*, Jingyi Shao*, Jianhao Feng \\ Faculty of Civil Engineering and Mechanics, Jiangsu University, Zhenjiang, China \\ Email: *ishexc@gmail.com, *sjy2028@126.com
}

How to cite this paper: He, X.C., Shao, J.Y. and Feng, J.H. (2021) Finite Element Simulation of Residual Stress Determination Based on Spherical Indentation Accumulation Morphology. World Journal of Mechanics, 11, 111-120.

https://doi.org/10.4236/wjm.2021.116009

Received: May 21, 2021

Accepted: June 7, 2021

Published: June 10, 2021

Copyright (c) 2021 by author(s) and Scientific Research Publishing Inc. This work is licensed under the Creative Commons Attribution International License (CC BY 4.0).

http://creativecommons.org/licenses/by/4.0/

\begin{abstract}
The introduction of residual stress during the processing of materials has an important impact on the properties of the materials, so it is important to accurately measure the residual stress of the material. This paper established a finite element model of spherical indentation under the action of non-equivalent biaxial residual stress. Then we extracted the full-field accumulation state near the indentation under different stress states from the simulation results and summarized the pile height distribution near the indentation under different stress states. From the simulation, we found that the maximum pile-up height near the indentation point presented a regular trend.
\end{abstract}

\section{Keywords}

Finite Element Method, Residual Stress, Spherical Indentation, Pile-Up Morphology

\section{Introduction}

The safety and reliability of major national infrastructure and public facilities, such as aircraft, high-speed rail, ships, and nuclear power plants, are the focus of society, and also affect the country's economic development. Alloys are often used as key components in these major infrastructure projects. For example, in modern advanced aero-engines, superalloy materials are widely used in core components such as turbine disks, turbine blades, and combustion Chambers, accounting for $40 \% \sim 60 \%$ of the total amount of engine materials. However, residual stress will be introduced into metal materials in the process of manufacture, processing, and surface treatment in different degrees [1] [2]. These introduced residual stresses not only have an important influence on the performance 
of material services, such as the crack strength, fatigue resistance, corrosion resistance, but also affect the dimensional stability of material components and the safety of the structure [3] [4]. Thus, it is of great significance to measure the residual stress of engineering materials accurately.

The traditional method for measuring residual stress can be divided into two groups, namely, mechanical stress-relaxation methods and physical-parameter analysis methods. Generally, mechanical stress-relaxation methods, including hole-drilling, slitting, and ring-core cutting techniques, are to release part of the residual stress, measure the amount of deformation caused by the change of residual stress, and then calculate the residual stress [5] [6] [7] [8]. However, the destructive nature of these methods limits the wide application of these techniques in the industry. Whereas, physical-parameter analysis methods, including $\mathrm{X}$-ray diffraction, neutron diffraction, ultrasonic wave, and magnetic Barkhausen noise, can measure residual stresses through the essential properties of materials and nondestructively, and some methods have been partially used in industrial fields [9] [10] [11]. However, these physical methods are limited by the intrinsic microstructure of the material and require the preparation of stress-free samples as reference. Additionally, X-ray diffraction and neutron diffraction methods cannot be directly applied to amorphous materials, which do not have a long-range ordered atomic structure.

To sum up, Oliver-Pharr method is the most widely used method for measuring material parameters and residual stresses in present researches [12] [13]. However, how to calculate the real contact area is the main concern when Oliver-Pharr method is used. Thus, the way to calculate the contact area or avoid the impact of the contact area has been studied by several researchers [14] [15]. Additionally, spherical indentation is more sensitive to stress effects than sharp indentation, but the amount of difference remains to be further studied [16]. Some researchers suggested that when calculating the residual stress of soft materials, the results obtained by the Suresh model and Lee model have a large margin of error and may not be suitable for calculation [17] [18]. Thus, the applicability of various calculation models is worth pondering.

In this paper, in order to study the residual stress inside the object, the relationship between the residual stress and the indentation profile was analyzed. The finite element method model was established to generate the pile-up morphology. The finite element simulation of the ridge shape of the indentation can accurately obtain the residual stress inside the object, which proves the effectiveness of the method.

\section{Numerical Models and Basic Assumptions}

Elastic/plastic indentation was simulated using the spherical indentation by the ABAQUS 6.14. The spherical indenter was modeled as an analytical rigid body and the indenter tip radius was assumed to be $1.25 \mathrm{~mm}$. Due to the symmetry of the indentation model, the $1 / 4$ axisymmetric model can be used to simplify the 
three-dimensional problem, as shown in Figure 1.

The established 3D model was modeled as a cuboid $10 \mathrm{~mm}$ high, $5 \mathrm{~mm}$ in thickness and $10 \mathrm{~mm}$ in radius by 42,180 hexahedral elements while the mesh properties are defined as C3D8R due to its high computational accuracy for displacement calculation. Roller boundary conditions were applied along the plane of symmetry and the bottom surface separately, a free surface was modeled at the outside of the model, and the interface between the indenter and the specimen was assumed that the friction coefficient is 0.15 .

Due to a large local deformation that may occur near the indentation area, thus, a very fine mesh is needed in the contact region to obtain accurate simulation. Correspondingly, a progressively coarser mesh was employed far away from the contact area. Besides, the indentation process was divided into two stages, that is, loading and unloading, so two static analysis steps are adopted to correspond to the indentation process. For the loading analysis step, the initial analysis step size is set to 0.001 , the maximum analysis step size is set to 0.01 , and the total analysis time is determined to be 1 . The setting of the unloading analysis step is the same as it is. All simulations were performed to a certain indentation depth and then withdrawing while the indentation was set to $0.125 \mathrm{~mm}$ based on the investigation results by $\mathrm{Lu}$ et al. [19].

The pre-stress of $-75 \mathrm{MPa},-50 \mathrm{MPa},-25 \mathrm{MPa}, 0 \mathrm{MPa}, 25 \mathrm{MPa}, 50 \mathrm{MPa}$, and $75 \mathrm{MPa}$ were applied to the $x$ and $y$ directions of the model during the simulation, so a total of 49 sets of finite element simulations were carried out. Pre-stress was applied to the model by the predefined field.

The output of the two finite element simulations included indentation load-displacement curves during the loading and unloading process, the pile-up morphology, and Mises stress contour after unloading. The maximum pile-up height can be obtained from the pile-up morphology after unloading. All

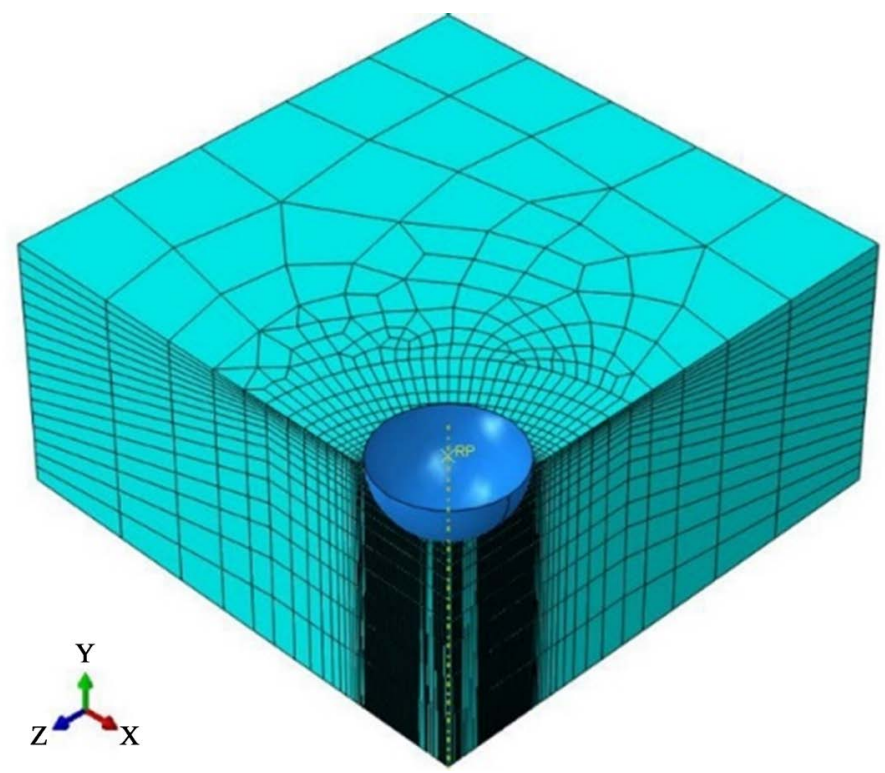

Figure 1. Schematic diagram of the finite element model. 
extracted data will be further analyzed and discussed in the following sections.

The material of the specimen for simulating was modeled as an elastic-plastic von Mises solid with isotropic hardening. The stress-strain relationship of the material can be described as

$$
\begin{cases}\sigma=E \varepsilon & \varepsilon \leq \varepsilon_{y} \\ \sigma=E \varepsilon_{y}^{1-n} \cdot \varepsilon^{n} & \varepsilon \geq \varepsilon_{y}\end{cases}
$$

where $n$ is the work hardening exponent, which is generally no more than 0.5 . In this study, the aluminum 2024 (2024 Al) was selected for simulation because it is prone to pile-up, and its material parameters can be obtained through a tensile experiment. Table 1 shows the basic material parameters of $2024 \mathrm{Al}$.

The stress-strain curve of $2024 \mathrm{Al}$ can be drawn according to the above material parameters, as shown in Figure 2. The constitutive behavior of $2024 \mathrm{Al}$ can be intuitively seen from Figure 2. In the elastic stage, the curve shows a linear trend, while the curve shows a parabolic change trend after entering the plastic stage.

\section{Simulation Results of Non-Equivalent Biaxial Residual Stress}

As described in Section 2, the indentation experiment with the indentation depth of $0.125 \mathrm{~mm}$ was simulated for the specimen under non-equivalent biaxial residual stress. After the indenter was unloaded, the full-field pile-up morphology near the indentation point was extracted, and the result was shown in Figure 3.

It can be seen from Figure 3 that the pile-up morphology after indentation unloading was closely related to the distribution of residual stress under the

Table 1. Material parameters of $2024 \mathrm{Al}$

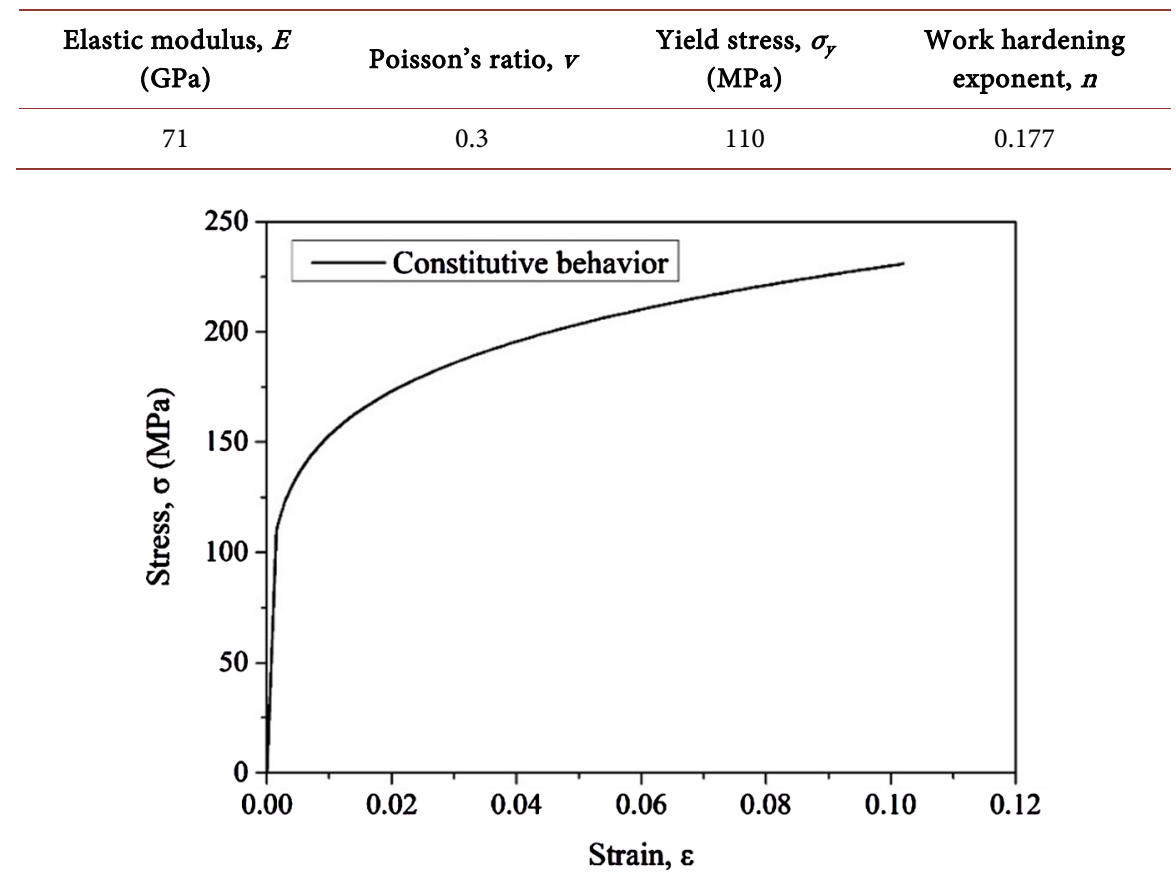

Figure 2. The constitutive behavior of $2024 \mathrm{Al}$. 


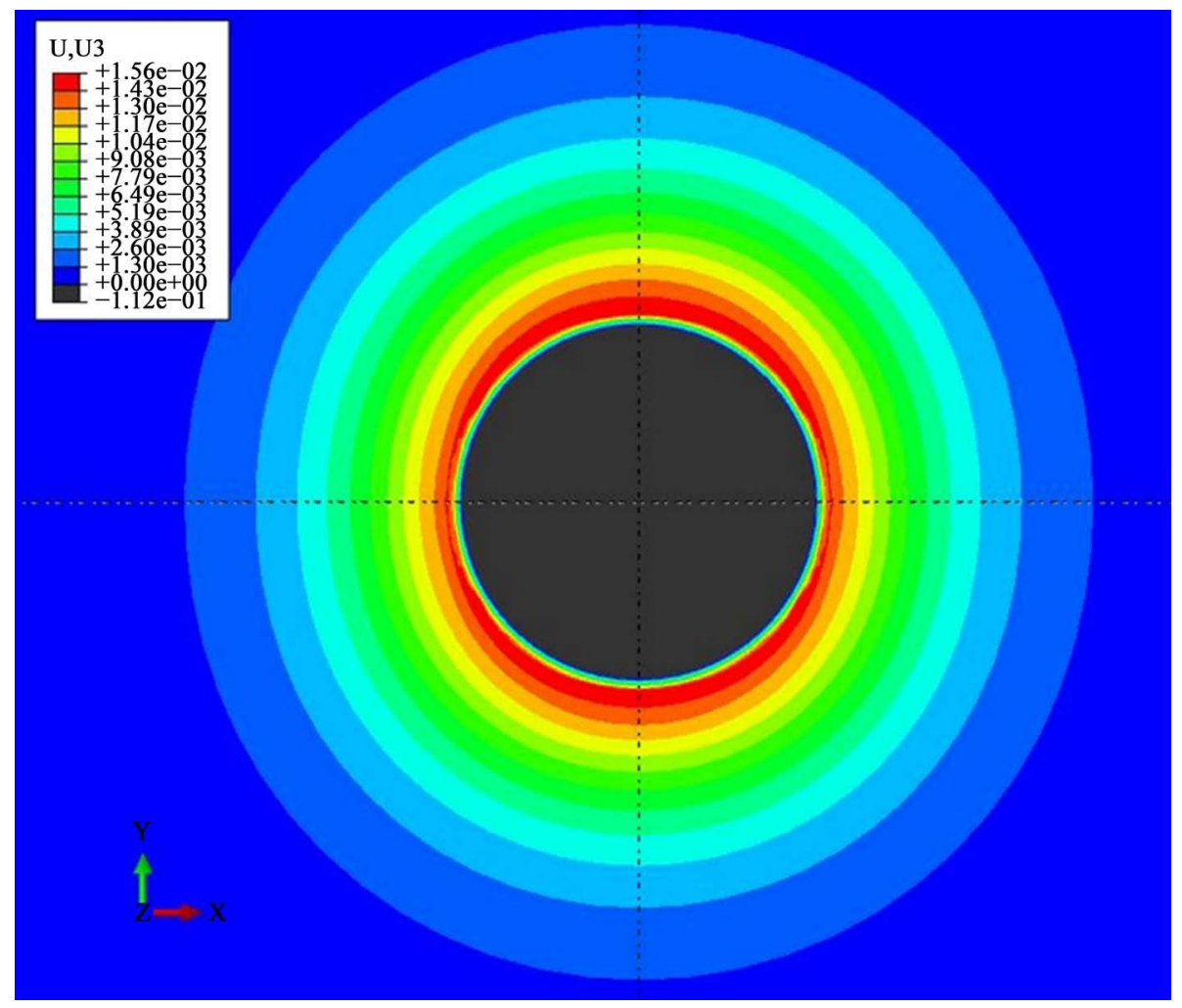

Figure 3. Full-field pile-up morphology $\left(\sigma_{x}=-75 \mathrm{MPa} \sigma_{y}=75 \mathrm{MPa}\right)$.

non-equivalent biaxial stress state. For the direction of the compressive stress, the slope of the pile-up morphology is larger, which indicates that the stacking phenomenon is more obvious, while for the direction of tensile force, the slope of the pile-up morphology is relatively small, indicating that the amount of pile-up there is small. It can be concluded that the tensile and compressive state of residual stress will affect the pile-up morphology near the indentation point.

In a further study, Figure 4 shows the change curves of pile-up height extracted in two main directions with the change of residual stress.

According to Figure 4, as the stress in the $y$-direction changes from the compressive stress state to the tensile stress state, both the maximum pile-up height in the $x$-direction and $y$-direction show a trend of gradual decrease. This is since tensile stress will reduce the pile-up height while compressive stress will increase the pile-up height. Also, it can be found that the reduction velocity of pile-up height in the $x$-direction is smaller than that in the $y$-direction, because the $y$-direction is the main direction of stress change, so it is more sensitive to stress change.

As can be seen from Figure 4, with the change of residual stress state, the pile-up height near the indentation point presents a regular trend of change. On this basis, the full-field pile-up morphologies near the indentation point under different stress distribution states were extracted, and it was found that the maximum pile-up height near the indentation point presented a regular trend as shown in Figure 5. 


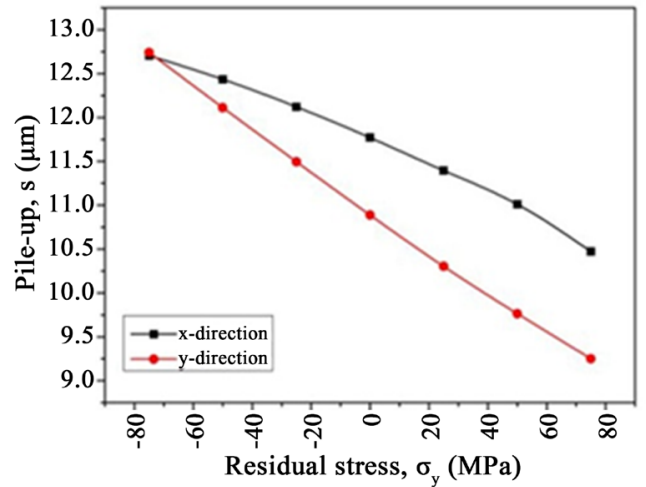

(a) $\sigma_{\mathrm{x}}=-75 \mathrm{MPa}$

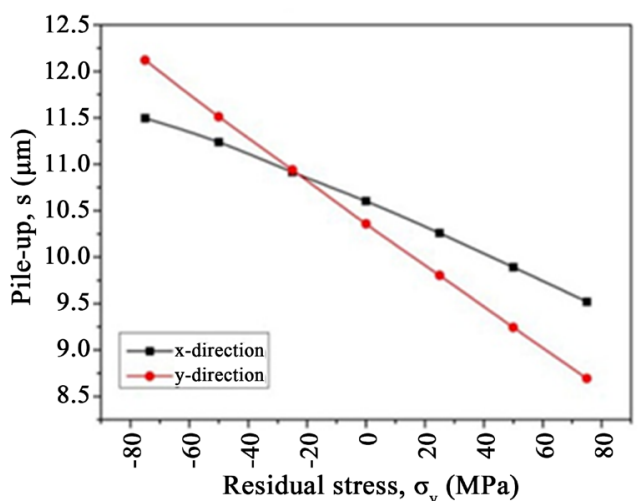

(c) $\sigma_{\mathrm{x}}=-25 \mathrm{MPa}$

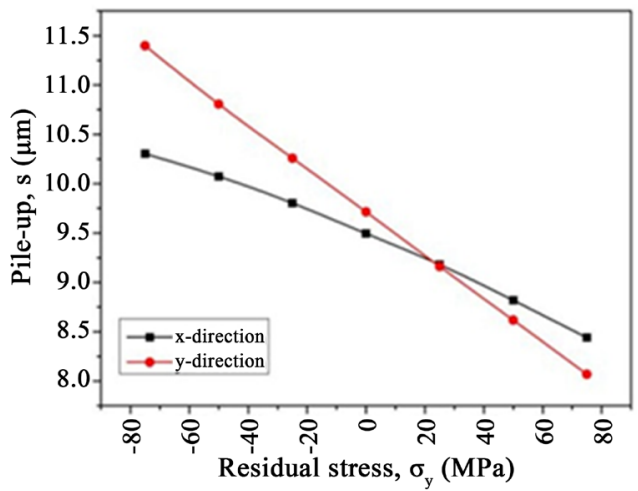

(e) $\sigma_{\mathrm{x}}=25 \mathrm{MPa}$

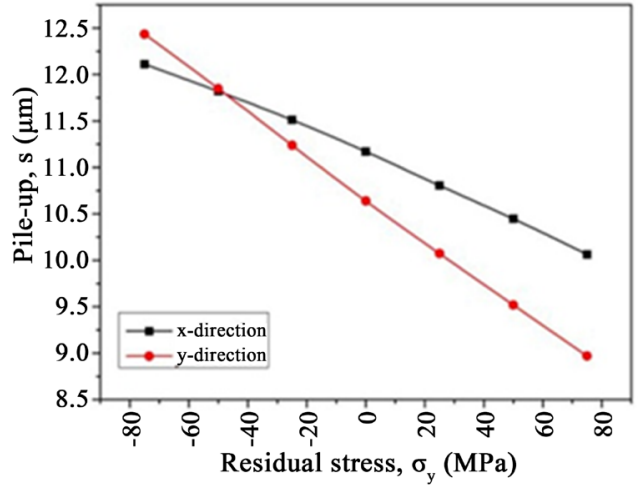

(b) $\sigma_{x}=-50 \mathrm{MPa}$

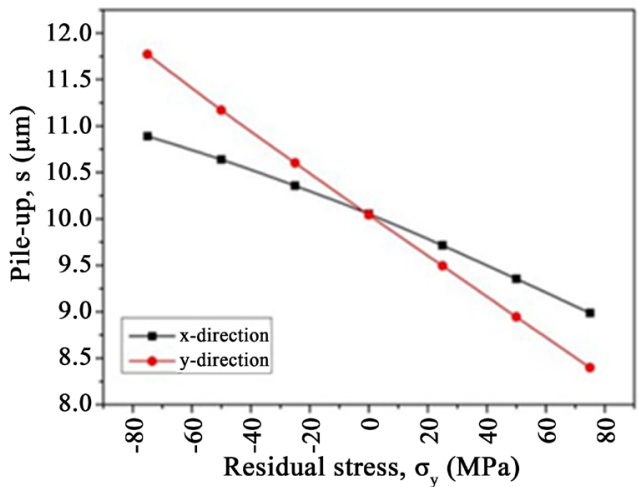

(d) $\sigma_{x}=0 \mathrm{MPa}$

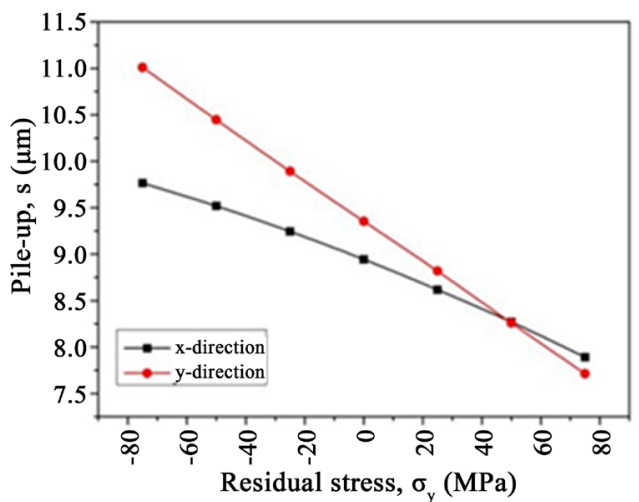

(f) $\sigma_{x}=50 \mathrm{MPa}$

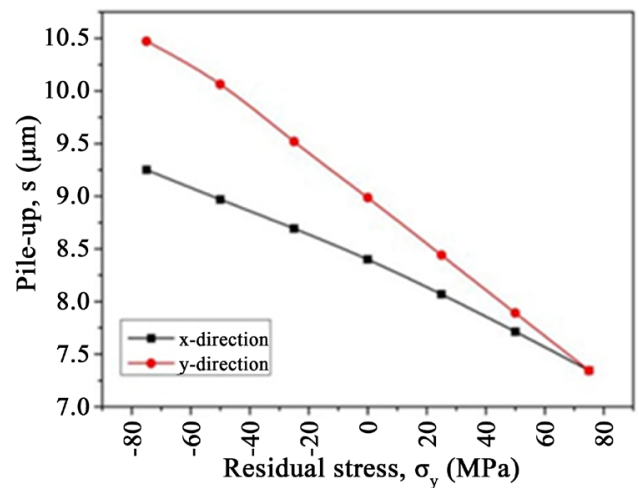

(g) $\sigma_{\mathrm{x}}=75 \mathrm{MPa}$

Figure 4. Schematic diagram of pile-up height versus $\sigma_{y^{*}}$ 


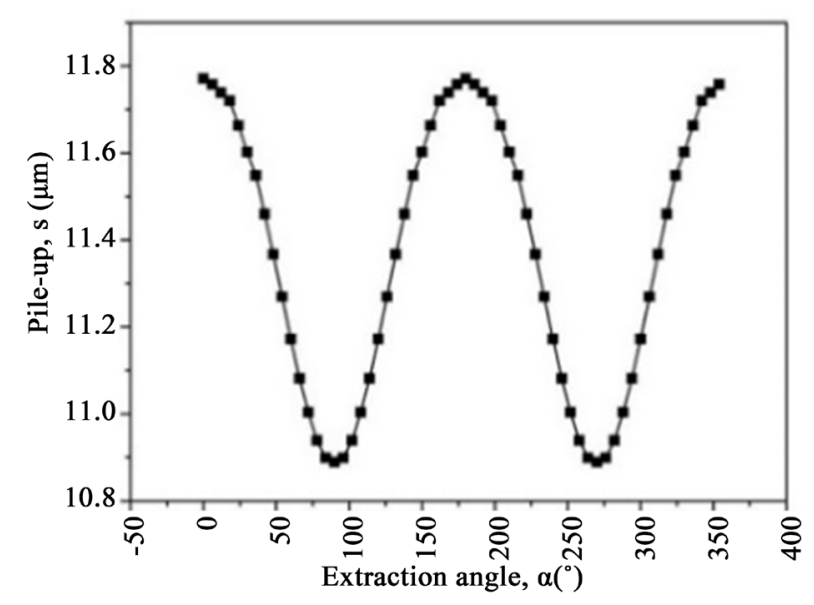

(a) $\sigma_{x}=-75 \mathrm{MPa} \sigma_{\mathrm{y}}=0 \mathrm{MPa}$

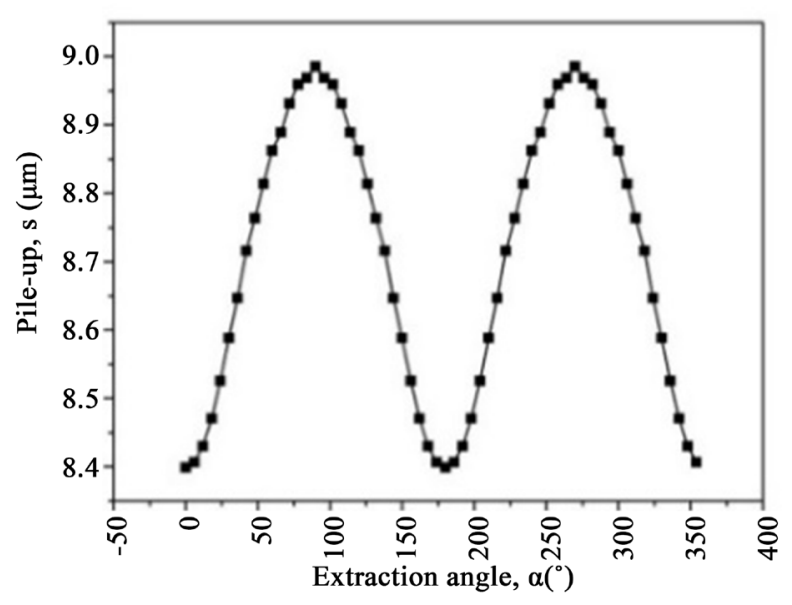

(b) $\sigma_{\mathrm{x}}=75 \mathrm{MPa} \sigma_{\mathrm{y}}=0 \mathrm{MPa}$

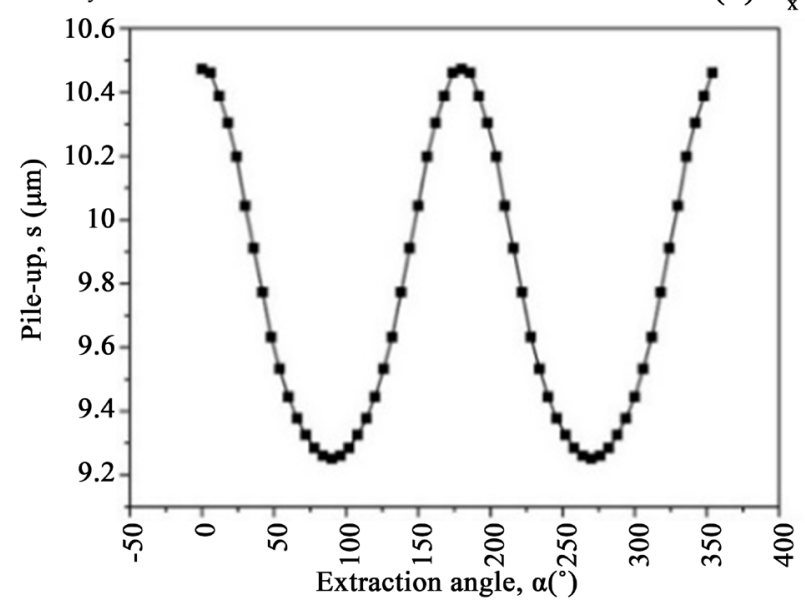

(c) $\sigma_{\mathrm{x}}=-75 \mathrm{MPa} \sigma_{\mathrm{y}}=75 \mathrm{MPa}$

Figure 5. Distribution diagram of maximum pile-up height around the indentation point.

Figure 5 shows the distribution of the maximum ridge height near the indentation point under three different stress states. In the figure, when $\alpha$ is 0 and 180 degrees, it corresponds to the $\mathrm{x}$ direction, and when $\alpha$ is 90 and 270 degrees, it corresponds to the y direction. Figure 5 (a) shows the distribution of the maximum swell height under uniaxial compression. It can be seen from the figure that the maximum swelling amount around the indentation point shows a regular sine function change. Among them, the swelling amount is the largest in the $\mathrm{x}$ direction, and the swelling amount is the smallest in the $\mathrm{y}$ direction. This is because for the uniaxial compression stress state in Figure 5(a), the swelling amount will increase in the main direction of the compressive stress. So the swelling amount will be greater compared to the unstressed state. Corresponding to it is the maximum ridge height distribution in the uniaxial tension state shown in Figure 5(b). It can be seen from the figure that under the action of tensile stress, the ridge amount in the $\mathrm{x}$ direction is significantly smaller than that of the unstressed. The bulge in the y direction doesn't change with stress. It is worth noting that, compared to the amount of uplift in the unstressed state, the 
amount of uplift in the two directions in the uniaxial compressive stress state is significantly greater than that in the unstressed state, while the amount of uplift in the uniaxial tensile stress state The swelling amount in both directions is significantly smaller than the swelling amount in the unstressed state. This shows that the residual stress state in one direction will also affect the uplift in the other direction.

For the two-way tension and compression stress state shown in Figure 5(c), it can be found that the uplift in the $\mathrm{x}$-direction is greater than the uplift in the unstressed state, and the uplift in the y-direction is less than that in the unstressed state. The amount of swelling, but compared to the swelling under uniaxial compression and uniaxial stress, the swelling under the two-directional tension and compression stress state is closer to the swelling under the unstressed state, which shows that the tension in the two directions Compressive stress will inhibit each other, weakening their ability to increase and decrease the amount of bumps.

\section{Conclusions}

The purpose of this paper is to study the relationship between the residual stress inside the object and the uplift height of the indentation. The finite element method is used to simulate the indentation ridge morphology of objects with different residual stresses. A variety of indentation finite element method simulations under different residual stresses were carried out, and the relationship between the uplift morphology and the residual stress was established, and the following conclusions were obtained.

1) The state of tension and compression of the residual stress will affect the accumulation morphology near the indentation point.

2) Tensile stress will reduce the pile-up height while compressive stress will increase the pile-up height.

3) The maximum swelling amount near the indentation point changes in a regular sinusoidal function. In the uniaxial stress state, the residual stress state in one direction will affect the uplift in the other direction while the stress in the two directions under the two-way tension and compression state will inhibit each other, weakening their ability to increase the huol and reduce the uplift.

\section{Acknowledgements}

The authors are grateful for financial support from the National Natural Science Foundation of China (Grant Nos. 11672345, 11872190, 11972014), and the Natural Science Foundation of Jiangsu Province (Grant Nos. BK 20190834).

\section{Conflicts of Interest}

The authors declare no conflicts of interest regarding the publication of this paper.

\section{References}

[1] Yang, Y.C. and Chang, E. (2001) Influence of Residual Stress on Bonding Strength 
and Fracture of Plasma-Sprayed Hydroxyapatite Coatings on Ti-6Al-4V Substrate. Biomaterials, 22, 1827-1836. https://doi.org/10.1016/S0142-9612(00)00364-1

[2] Laamouri, A., Sidhom, H. and Braham, C. (2013) Evaluation of Residual Stress Relaxation and Its Effect on Fatigue Strength of AISI 316L Stainless Steel Ground Surfaces: Experimental and Numerical Approaches. International Journal of Fatigue, 48, 109-121. https://doi.org/10.1016/j.ijfatigue.2012.10.008

[3] Toribio, J. (1998) Residual Stress Effects in Stress-Corrosion Cracking. Journal of Materials Engineering and Performance, 7, 173-182. https://doi.org/10.1361/105994998770347891

[4] Mao, W.G., Wan, J., Dai, C.Y., Ding, J., Zhang, Y., Zhou, Y.C. and Lu, C. (2012) Evaluation of Microhardness, Fracture Toughness and Residual Stress in a Thermal Barrier Coating System: A Modified Vickers Indentation Technique. Surface and Coatings Technology, 206, 4455-4461. https://doi.org/10.1016/j.surfcoat.2012.02.060

[5] Mainjot, A.K., Schajer, G.S., Vanheusden, A.J. and Sadoun, M.J. (2011) Residual Stress Measurement in Veneering Ceramic by Hole-Drilling. Dental Materials, 27, 439-444. https://doi.org/10.1016/j.dental.2010.12.002

[6] Montay, G., Cherouat, A., Lu, J., Baradel, N. and Bianchi, L. (2002) Development of the High-Precision Incremental-Step Hole-Drilling Method for the Study of Residual Stress in Multi-Layer Materials: Influence of Temperature and Substrate on $\mathrm{ZrO}_{2}-\mathrm{Y}_{2} \mathrm{O}_{3} 8$ wt.\% Coatings. Surface and Coatings Technology, 155, 152-160. https://doi.org/10.1016/S0257-8972(01)01718-2

[7] Watson, C. (2007) Home-School Partnership and the Construction of Deviance: Being and Becoming the Goldfish Family. Journal of Research in Special Educational Needs, 11, 20-29.

[8] Masláková, K., Trebuňa, F., Frankovský, P. and Binda, M. (2012) Applications of the Strain Gauge for Determination of Residual Stresses Using Ring-Core Method. Procedia Engineering, 48, 396-401. https://doi.org/10.1016/j.proeng.2012.09.531

[9] Mahmoodi, M., Sedighi, M. and Tanner, D.A. (2012) Investigation of through Thickness Residual Stress Distribution in Equal Channel Angular Rolled Al 5083 Alloy by Layer Removal Technique and X-Ray Diffraction. Materials \& Design, 40, 516-520. https://doi.org/10.1016/j.matdes.2012.03.029

[10] Hu, E., He, Y. and Chen, Y. (2009) Experimental Study on the Surface Stress Measurement with Rayleigh Wave Detection Technique. Applied Acoustics, 70, 356-360. https://doi.org/10.1016/j.apacoust.2008.03.002

[11] Gauthier, J., Krause, T.W. and Atherton, D.L. (1998) Measurement of Residual Stress in Steel Using the Magnetic Barkhausen Noise Technique. NDT \& E International, 31, 23-31. https://doi.org/10.1016/S0963-8695(97)00023-6

[12] Oliver, W.C. and Pharr, G.M. (1992) An Improved Technique for Determining Hardness and Elastic Modulus Using Load and Displacement Sensing Indentation Experiments. Journal of Materials Research, 7, 1564-1583.

https://doi.org/10.1557/JMR.1992.1564

[13] Swadener, J.G., Taljat, B. and Pharr, G.M. (2001) Measurement of Residual Stress by Load and Depth Sensing Indentation with Spherical Indenters. Journal of Materials Research, 16, 2091-2102. https://doi.org/10.1557/JMR.2001.0286

[14] Peng, G., Feng, Y., Huan, Y., Zhang, T., Ma, Y. and Lu, Z. (2018) Spherical Indentation Method for Estimating Equibiaxial Residual Stress and Elastic-Plastic Properties of Metals Simultaneously. Journal of Materials Research, 33, 884-897. https://doi.org/10.1557/jmr.2018.57

[15] Zhu, L.N., Xu, B.S., Wang, H.D. and Wang, C.B. (2010) Measurement of Residual 
stress in Quenched 1045 Steel by the Nanoindentation Method. Materials Characterization, 61, 1359-1362. https://doi.org/10.1016/j.matchar.2010.09.006

[16] Taljat, B. and Pharr, G.M. (2000) Measurement of Residual Stresses by Load and Depth Sensing Spherical Indentation. MRS Online Proceeding Library, 594, 2091-2102. https://doi.org/10.1557/PROC-594-519

[17] Liu, B.L., Weng, W.X., Li, Q., Wang, Y.M. and Qiao, X. (2018) Influence of Pores on Mechanical Properties of Plasma Sprayed Coatings: Case Study of YSZ Thermal Barrier Coatings. Ceramics International, 44, 21564-21577. https://doi.org/10.1016/j.ceramint.2018.08.220

[18] Liu, D., Gong, Q., Lei, J., Zhang, B., Shen, L. and He, Y. (2015) A Novel Method for Determining Surface Residual Stress Components and Their Directions in Spherical Indentation. Journal of Materials Research, 30, 1078-1089.

https://doi.org/10.1557/jmr.2015.87

[19] Zhu, L.N., Xu, B.S., Wang, H.D. and Wang, C.B. (2014) Measurement of Residual Stresses Using Nanoindentation Method. Critical Reviews in Solid State and Materials Sciences, 40, 77-89. https://doi.org/10.1080/10408436.2014.940442 